\title{
Diagnóstico y evaluación de las viviendas en el patrimonio arquitectónico de Mendoza, Argentina
}

\author{
Silvia A. Cirvini \\ Lorena Manzini
}

Introducción

Mendoza, Nuevo Valle de Rioja (1561), fue una de las primeras fundaciones en el actual territorio de la República Argentina en el piedemonte de la cordillera de los Andes, oasis irrigado por el río Mendoza. La ciudad de Mendoza tuvo un lento crecimiento durante tres siglos hasta el destructivo terremoto de 1861 que la dejó en ruinas. El período de la reconstrucción, coincidió con la puesta en marcha de un proyecto modernizador, la ampliación del área cultivada y el funcionamiento de la red ferroviaria acompañada de un creciente ingreso de inmigrantes, todos ingredientes para un vertiginoso crecimiento hacia fines del siglo XIX.

El territorio de la entonces histórica ciudad se desmembró en tres departamentos: Ciudad, Las Heras y Guaymallén, y otros nuevos crecieron hacia el sudoeste, como consecuencia de la rápida urbanización del oasis agrícola: Godoy Cruz, Luján y Maipú a lo largo del siglo XX progresivamente se fueron consolidando a partir de incipientes núcleos, formando así un suburbio continuo y extendido (Figura 1).

El área metropolitana de Mendoza (AMM) está comprendida en la actualidad por los seis departa-

1. El proyecto estuvo organizado sobre dos grandes ejes articulados. El primero consistió esencialmente en identificar el conjunto de bienes culturales en el territorio de los seis departamentos que conforman el conurbano mendocino y elaborar una base de datos (georreferenciada) con información histórica, científica y técnica acerca de los bienes. El segundo eje consistió básicamente en la evaluación de las características, posibilidades y límites de este patrimonio con el fin de proponer directrices, diseñar estrategias sobre las cuales orientar la conservación y la activación patrimonial. Cf. Cirvini, S. y Raffa, C. (2010). mentos que definen el conurbano: Capital, Godoy Cruz, Guaymallén, Luján, Maipú y Las Heras. Constituye la cuarta aglomeración de la Argentina actual, luego de Buenos Aires, Córdoba y Rosario (Figura 2).

Este trabajo se origina en el marco de la siguiente hipótesis general del proyecto PICT 13 - 14022 "Bienes culturales y desarrollo local en el área metropolitana de Mendoza (AMM)"':

El Patrimonio Cultural asociado al Territorio (edificios, sitios, paisajes) constituye un recurso y una herramienta en los procesos de desarrollo local, que en el caso del área metropolitana de Mendoza no es tenido en cuenta por los principales actores involucrados. Una evaluación de este conjunto de bienes y de sus características como recurso permitirá la activación patrimonial y su consiguiente valorización e integración.

Es sabido que el patrimonio cultural arquitectónico (PCA) constituye una herramienta poderosa en el desarrollo local en los procesos de reactivación frente a las crisis socioeconómicas, en las diferentes

* Cómo citar este artículo: Cirvini, S. y Manzini, L. (2016). Diagnóstico y evaluación de las viviendas en el patrimonio arquitectónico de Mendoza, Argentina. Apuntes, 29(1), 46-61. http://dx.doi.org/10.11144/Javeriana.apc29-1.devp 


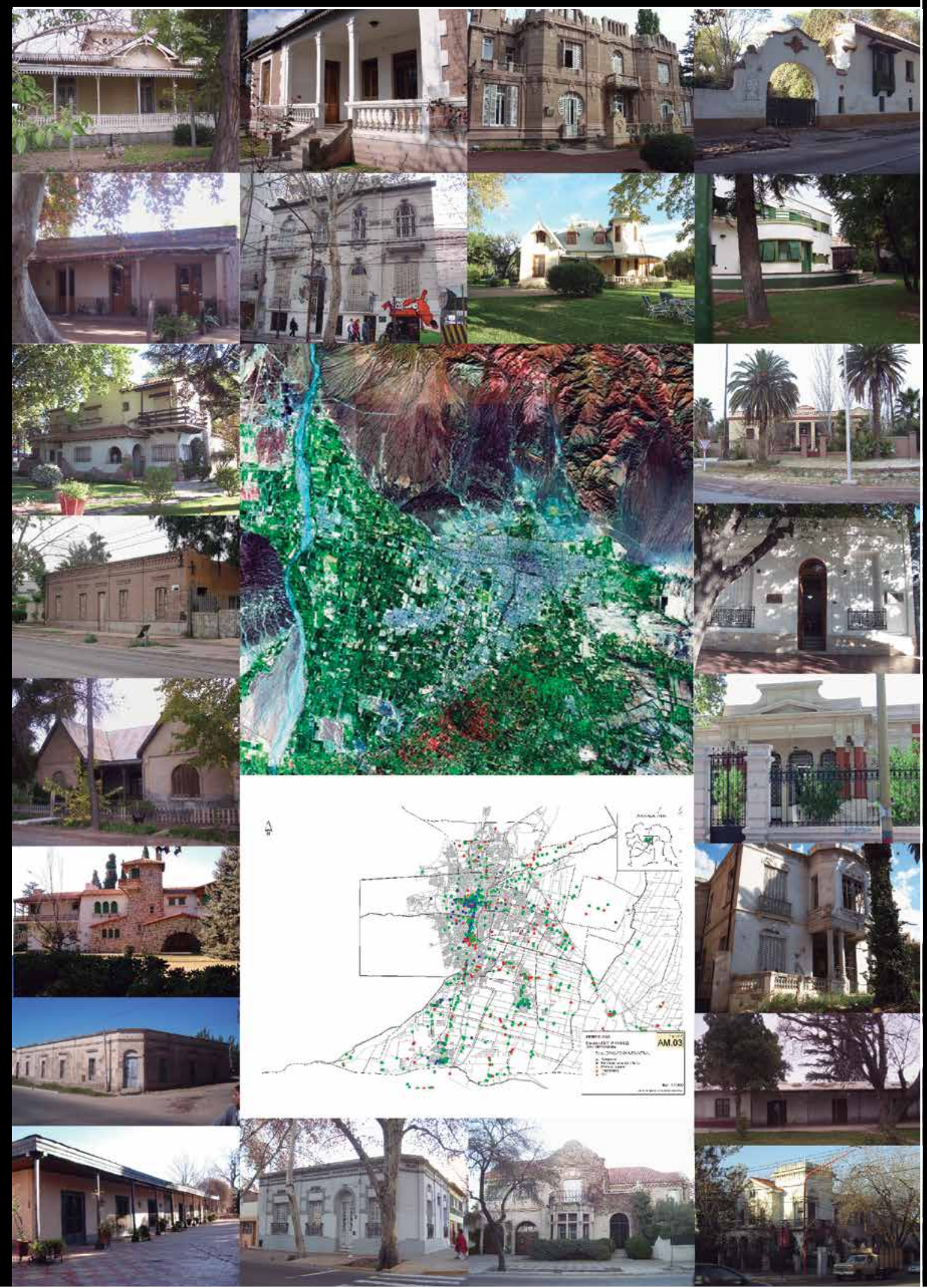

Mosaico de viviendas en el patrimonio arquitectónico de Mendoza.

Fuente:

Proyecto PICT 13 - 14022

dirigido por Silvia Cirvini 


\title{
Diagnóstico y evaluación de las viviendas en el patrimonio arquitectónico de Mendoza, Argentina
}

\author{
Diagnosis and Evaluation of Houses in the Architectural Heritage of Mendoza, Argentina \\ Diagnóstico e avaliação de casas do património arquitetônico de Mendoza, Argentina
}

Silvia A. Cirvin

scirvini@mendoza-conicet.gob.ar

Arquitecta, Universidad de Mendoza. Doctora en Arquitectura, Universidad Nacional de Tucumán. Investigadora principal del Conicet, Incihusa (Instituto de Ciencias Humanas, Sociales y Ambientales) y del Centro Científico Tecnológico Conicet en Mendoza, CCT - Mendoza. Investigadora histórica en torno de la arquitectura y el urbanismo de los siglos XIX y XX y en conservación patrimonial. Dirige una unidad de trabajo dedicada a la investigación histórica y tecnológica en torno a la arquitectura regional con transferencia en el campo de la restauración de edificios en áreas sísmicas. Es docente de posgrado en maestrías y doctorados de universidades nacionales y privadas. Experta y formadora en gestión, interpretación y activación del patrimonio cultural para su integración a la vida del presente.

Lorena Manzini

Imanzini@mendoza-conicet.gob.ar

Arquitecta, Universidad de Mendoza. Doctora en Arquitectura, Universidad de Mendoza. Investigadora asistente del Conicet, Incihusa (Instituto de Ciencias Humanas, Sociales y Ambientales) y del Centro Científico Tecnológico Conicet en Mendoza, CCT - Mendoza. Su labor en investigación se ha desarrollado en el marco de la conservación del patrimonio, la historia de Mendoza, Argentina, el significado cultural del patrimonio industrial en esa ciudad y en la historia vitivinícola y habitacional. Fue becaria inicial de la ANPCyT y becaria de posgrado tipo Il y posdoctoral del Conicet, Argentina. Fue docente en la Facultad de Arquitectura, Urbanismo y Diseño de la Universidad de Mendoza en la cátedra Historia de la Arquitectura y en Urbanismo 2. Es miembro de la Comisión Directiva de Icomos Argentina como subdelegada de la Región Cuyo.

Resumen

Este artículo aborda el análisis y la evaluación de una fracción específica de la producción arquitectónica, las viviendas de valor patrimonial, dentro del territorio del área metropolitana de Mendoza, Argentina. En su desarrollo hemos considerado como fuentes, por una parte, investigaciones anteriores que han permitido comprender el desarrollo histórico y la evolución de este tipo de edificios en la arquitectura de la ciudad, y por otra, apelamos a los datos primarios de un proyecto concluido recientemente sobre el patrimonio arquitectónico del área metropolitana de Mendoza. El análisis y evaluación de las características arquitectónicas, posibilidades y límites de este conjunto de viviendas, contribuye en la proposición de directrices y en el diseño de estrategias sobre las cuales orientar la conservación y la puesta en valor de los bienes. Lamentablemente, en la última década se ha incrementado la pérdida de estas obras, ya sea por desvalorización de su importancia cultural como por las fuertes presiones del mercado inmobiliario, por lo cual se conservan cada vez menos ejemplares de cada agrupamiento tipológico. La investigación histórica ha brindado en nuestro trabajo el marco interpretativo de los bienes patrimoniales relevados, y nos ha permitido dibujar un mapa explicativo de la evolución particular de este tipo de edificios: las viviendas. Si la historia nos permite reconstruir lo que fue, lo patrimonial nos permite en el presente evaluar lo que queda, como testimonio fragmentario que puede actuar de soporte de la memoria histórica vinculada a las formas del habitar en el desarrollo socio cultural de la ciudad y su enclave en el oasis norte de la provincia.

Palabras clave: viviendas; patrimonio arquitectónico; recurso; valoración; evaluación

Abstract

This article presents the analysis and assessment of a specific portion of the architectural production in Mendoza: houses with a great historical value within the metropolitan area of Mendoza, Argentina. As source material, we considered previous research studies, which have enabled us to understand the historical evolution and the different kinds of buildings around the region, as well as some primary information from a project on the architectural heritage of the metropolitan area of Mendoza, recently finished. The analysis and evaluation of the architectural features, possibilities and limits of this set of housing contributes proposing guidelines and in designing strategies which guide the conservation and valorization of this heritage. Regrettably, these architectural master pieces have been lost during the last decade, due to a depreciation of their cultural value and strong pressures from the real estate market. For these reasons, fewer and fewer buildings of this type are kept in place. Historical research has granted an interpretation framework of all the architectural assets which have been classified, allowing us to draw an explanatory diagram of the particular evolution of these constructions: the houses. If History enables us to reconstruct "what it was", then patrimony enables us to analyze "what remains" at present, as a piecemeal testimony of the historical memory in relation to the different forms of living within a certain social and cultural development of a city and its location in the Northern oasis of Mendoza, in the Center-West of Argentina.

Keywords: houses; architectural heritage; resource; valuation; assessment

Resumo

Este artigo discute a análise e avaliação de uma fração específica da arquitetura de produção: capital próprio habitação, no território da área metropolitana de Mendoza, Argentina. Em seu desenvolvimento, temos considerado como fontes, por um lado, pesquisas anteriores que nos permitiu compreender o desenvolvimento histórico e evolução deste tipo de edifícios na arquitetura da cidade e em segundo lugar, apelamos aos dados preliminares de um projeto recém-concluído em o património arquitetônico da região metropolitana de Mendoza. A análise e avaliação das características arquitetônicas, possibilidades e limites desse conjunto de contributos de habitação propondo diretrizes e na elaboração de estratégias que orientam a conservação e valorização deste património. Infelizmente na última década aumentou a perda dessas obras, seja através de desvalorização da sua importância cultural como as fortes pressões no mercado da habitação, aumentando assim preservadas menos cópias de cada agrupamento tipológica. A pesquisa histórica tem dado o nosso trabalho no quadro interpretativo dos bens do património listadas, e permitiu-nos para desenhar um mapa explicativo da evolução particular deste tipo de edifícios: casas. Se a história nos permite reconstruir o que era, o que nos permite património desta avaliar o que permanece, como testemunho fragmentária que pode atuar em apoio da memória histórica ligada a formas de habitação no desenvolvimento sócio-cultural da cidade e sua enclave oásis no norte da província.

Palavras-chave: habitação; património arquitetônico; recursos; valoração; avaliação

doi: 10.11144/Javeriana.apc29-1.devp 
escalas: un edificio, conjuntos, un parque, áreas urbanas o rurales, el paisaje, etc. Sin embargo, en la provincia de Mendoza, particularmente en el caso del área metropolitana de Mendoza que nos ocupa, este factor es sistemáticamente desconsiderado por los principales actores sociales involucrados: los depositarios de los bienes, los responsables de las políticas públicas y la industria del turismo.

Este desconocimiento o desvalorización del papel dinamizador que puede adquirir este factor, se debe, en primer lugar, a razones socioculturales: desconocimiento del valor de los bienes, mitos y prejuicios en torno a la conveniencia de la conservación de edificios antiguos en área sísmica, estereotipos acerca de la noción de "progreso", evaluaciones erróneas de la relación costo-beneficio en la opción entre restaurar o construir algo nuevo, etc. En segundo lugar, la situación del PCA en el caso mendocino se agrava notablemente, hasta el límite de la pérdida total, porque operan por acción u omisión otras fuerzas como: las presiones y distorsiones del mercado inmobiliario respecto del uso y valor del suelo, la ausencia del papel regulador del Estado sobre el espacio público, la desvinculación entre el campo científico-técnico y la dirigencia política, la ausencia de un horizonte estratégico tanto a nivel gubernamental como empresario respecto del proyecto de sociedad al que se orienta el desarrollo y, finalmente, las diversas y contradictorias acciones que los distintos sectores de la población imprimen sobre el espacio urbano y rural en la búsqueda de efímeras soluciones a la crisis socioeconómica.

Existe un valioso conjunto de bienes que constituyen un recurso de grandes posibilidades que los empresarios y dirigentes mendocinos no alcanzan a vislumbrar. Paradójicamente, la gente común, de los barrios o las poblaciones del conurbano, sostiene una relación identificatoria positiva con el lugar donde viven, valorizan en forma intuitiva la calidad del ambiente que les proporciona el disfrute de ciertos bienes culturales, sin embargo, en la mayoría de los casos no tienen las herramientas y los medios para protegerlos, integrarlos a la vida del presente y utilizarlos para revertir situaciones de crisis. Existen edificios desocupados y a la vez instituciones comunitarias que necesitan un ámbito dónde funcionar y también valiosos antiguos inmuebles de propiedad estatal en situación de abandono

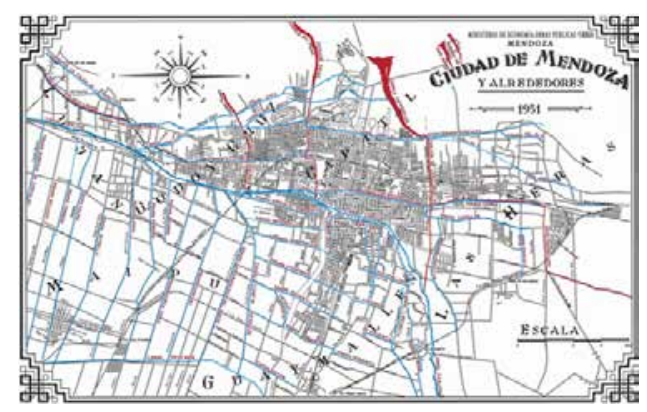

Figura 1:

Área metropolitana

de Mendoza hacia

mediados del siglo XX.

Fuente:

Ponte, 2007

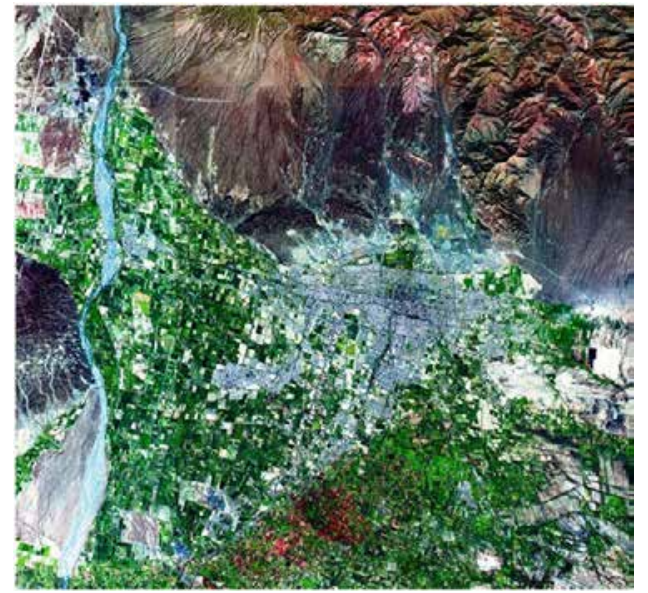

Figura 2:

Área metropolitana de Mendoza, vista de zona ocupada $y$ oasis río Mendoza.

Fuente:

Google Earth, 2009

cuando simultáneamente se pagan importantes sumas en alquileres para el funcionamiento de oficinas estatales.

En este marco y ante la relevancia de los edificios destinados a viviendas (en su gran mayoría unifamiliares) dentro del patrimonio arquitectónico de una ciudad intermedia como Mendoza, proponemos la formulación de un pronóstico respecto de su conservación, en el marco de un gran recambio edilicio y de los contextos actuales de asignación de valor a este tipo de obras. Los datos utilizados en este artículo provienen, mayoritariamente, del proyecto PICT 13 - 14022 ya mencionado.

Un alto porcentaje del conjunto de los bienes arquitectónicos relevados (2009/2010) son viviendas (60\%) lo cual nos permite efectuar una evaluación particular y específica de este tipo de edificios.

Sobre la base de los resultados obtenidos en este proyecto proponemos analizar el patrimonio de las viviendas dentro del AMM, y relacionar, en cuanto sea posible, este valioso conjunto de obras tanto con el proceso de ocupación del territorio como con la cultura arquitectónica de la región.

Una de las características de los edificios patrimoniales es su carácter de documento que testimonia no solo una época sino las dinámicas 


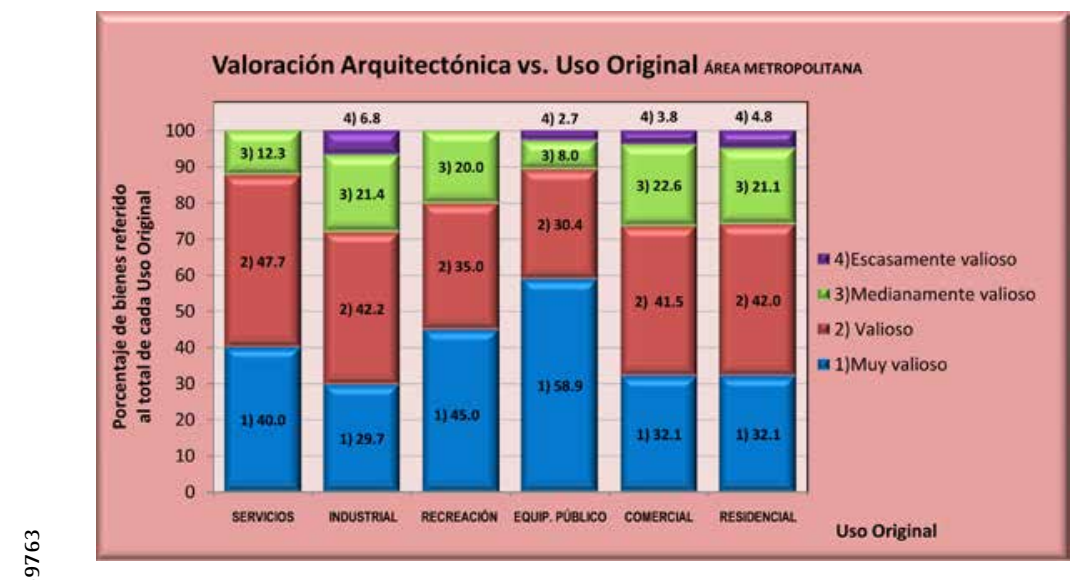

Figura 3: culturales, sociales y territoriales de las que tamValoración bién es testimonio. Esta capacidad documental arquitectónica por agrupamiento de usos.

Fuente: Silvia Cirvini

2. Los criterios de valoración empleados en el presente trabajo se encuentran basados a los implementados en el marco de proyecto PICT 13 - 14022 que integra los principales criterios discutidos en el ámbito académico y de especialistas en patrimonio. Recomendamos la lectura de Cirvini S. et al. (2009)

3. Destacamos que el presente trabajo se focaliza en el análisis de la dimensión material del patrimonio habitacional del área metropolitana de Mendoza; el desarrollo del valor simbólico, debido a su magnitud y tipo de tratamiento, queda pendiente para trabajos futuros.

4. Entendemos por "departamento" cada una de las demarcaciones en que se subdivide el territorio del área metropolitana de Mendoza (AMM), que poseen autonomía administrativa y política, cuyo respectivo origen tiene una historia ligada a la evolución de la ocupación del oasis norte del río Mendoza. En el área metropolitana de Mendoza son seis: la histórica ciudad de Mendoza (fundada en 1561) se desmembró en el siglo XIX en tres departamentos: Ciudad, Las Heras y Guaymallén, a la vez que surgieron otros nuevos como consecuencia de la rápida urbanización y crecimiento del oasis agrícola: Godoy Cruz, Luján y Maipú se consolidaron a partir de incipientes núcleos. de desarrollo de un vasto conjunto de edificios que registra los avatares de la arquitectura de más de un siglo y que permite comprender su adaptabilidad en el uso al mundo del presente. Finalmente, muchas de las obras acumulan un importante valor simbólico en tanto se encuentran ligadas a tópicos centrales del desarrollo cultural de la región: la economía (la vitivinicultura), el marco natural (los sismos y el oasis), el progreso (los materiales y el confort).

\section{Procesamiento de datos y análisis de variables}

El inventario realizado, en lo que se refiere a patrimonio arquitectónico, tuvo varias etapas y en su desarrollo fueron relevadas, evaluadas y ponderadas las variables que consideramos más significativas de acuerdo con los objetivos del proyecto. Luego se almacenaron digitalmente los resultados y datos construidos. Esta base de datos informatizada fue vinculada con otra georreferenciada, lo que hizo posible llevar al territorio la selección de las diferentes variables.

La parte final del procesamiento fue la estadística. A partir de las diferentes hipótesis se evaluaron cuantitativamente las variables más significativas para los objetivos del proyecto: propiedad, usos, ocupación, tipología arquitectónica y estructural, estado de conservación, calidad ambiental, depositarios, etc.

Paralelamente al análisis de la localización territorial y a partir de las planillas de cálculo se obtuvieron gráficos estadísticos tipificados por variable o grupo, que nos fueron mostrando su evolución en el tiempo y la vinculación entre ellas (Figura 3).

Además, en sistemas cartesianos, se graficaron pares de variables, cuya relación nos interesaba analizar, por ejemplo, la curva resultante de bienes relevados según la fecha de construcción y tipo funcional o el estado general de la estructura del edificio en función de su datación.

El procesamiento estadístico de los datos por departamento ${ }^{4}$ y en el AMM, junto al análisis de los mapas obtenidos con la base georreferenciada, permitieron evaluar en conjunto los bienes relevados y corroborar las hipótesis planteadas respecto a sus posibilidades como recurso.

En primer lugar, se analizaron las diferentes series de gráficos estadísticos de acuerdo con las variables definidas: propiedad, uso, ma- 


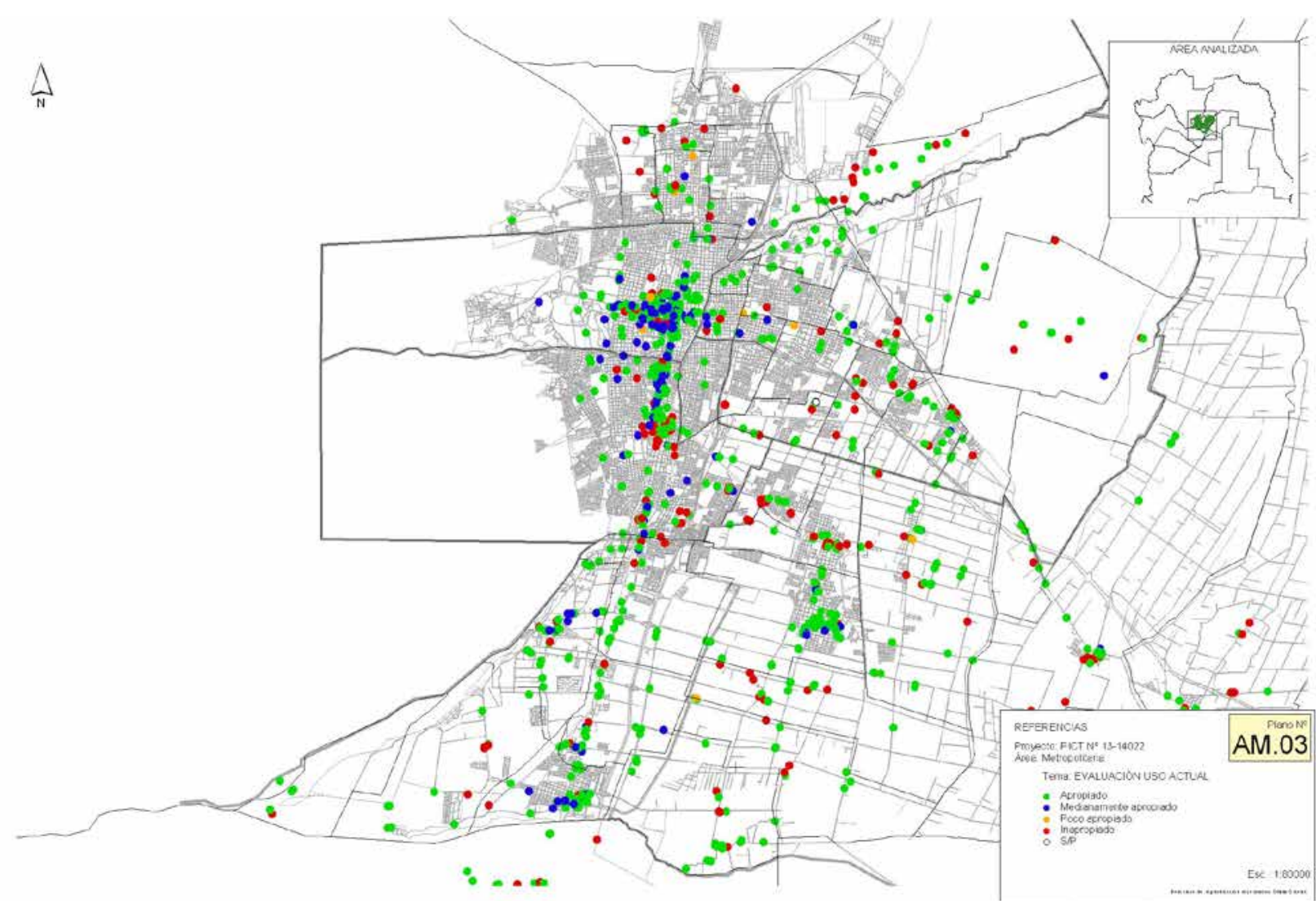

terialidad, ocupación, valoración, etc. Buscamos describir y analizar el patrimonio relevado para poder caracterizarlo y evaluarlo en sí mismo como recurso cultural y en relación con el conjunto de bienes del AMM. Es decir, se realizó el análisis de cada una de estas variables en cada uno de los departamentos buscando descubrir qué relaciones significativas mantiene con otras variables, por ejemplo, la propiedad con el uso, los materiales de construcción con el estado de conservación, etc. En forma paralela se realizó un análisis comparativo de cada grupo de variables en todos los departamentos y de cada uno con el área metropolitana.

Este análisis permitió ir corroborando o no las hipótesis de trabajo que formulamos (y reformulamos durante el desarrollo del proyecto) al vincular las diferentes variables significativas para la elaboración de un diagnóstico.

Asimismo, este análisis hizo posible la definición de lo específico de cada departamento, las particularidades, las diferencias de un mismo tipo de edificio patrimonial en cada municipio (diferencias que podían actuar a favor y en contra del recurso patrimonial), los matices dentro de un mismo agrupamiento tipológico (por ejemplo, no tiene las mismas características el patrimonio vitivinícola en Las Heras y Guaymallén que en Luján y Maipú). Esta última etapa del análisis ha dejado planteadas nuevas preguntas y formuladas nuevas hipótesis que sin duda buscaremos desarrollar en trabajos futuros.

Mapas patrimoniales

La elaboración de mapas patrimoniales permitió realizar un análisis de la distribución territorial de los bienes en cada departamento y en el área metropolitana en su conjunto. Se correlacionaron la distribución y la densidad de los bienes en general y en los diferentes agrupamientos de cada categoría. Se evaluó el grado de dispersión, la densificación y la distribución en cada departamento y en el área metropolitana en general (ver a modo de ejemplo la Figura 4, que corresponde a Mapa Patrimonial núm. 6: Evaluación uso actual).

Esta cartografía obtenida como resultado del proyecto permite futuras aplicaciones para la elaboración de normativa, para la formulación de itinerarios y rutas culturales y para fundamentar todo plan de salvaguarda y manejo de los bienes involucrados. Asimismo, los mapas permiten evaluar y correlacionar las variables analizadas.
Figura 4:

Mapa patrimonial 6:

Área metropolitana.

Evaluación del uso actual.

Fuente:

Silvia Cirvini 

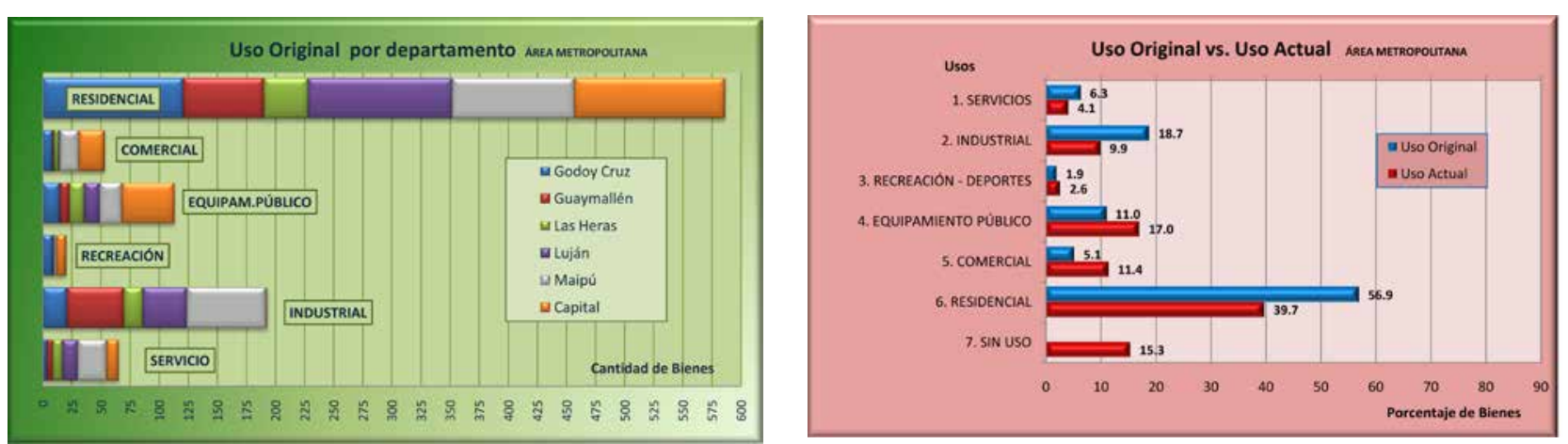

5. Metadata:

Uso original: es el tipo funcional originario del edificio, uso para el cual fue construido. Las categorías consideradas refieren a un uso general y un uso específico. En el caso de uso general residencial, los subtipos de uso específico

fueron: 1. Vivienda unifamiliar (comprende aquellos edificios para una sola

familia, nuclear o extendida, como casas rurales, urbanas, chalets, etc.), 2. Vivienda colectiva, 3. Vivienda comunitaria y 4 . Hotel - Residencial - Pensión - Hostería. Uso actual: es el uso que posee el edificio en el presente. Las categorías utilizadas son las mismas que para el uso original con el agregado de una categoría: sin uso.

6. Metadata: Uso original: ver nota anterior.

Datación: se considera la fecha de construcción o proyecto (la más antigua), puede ser documentada o estimada. Para la elaboración de los gráficos se consideró el total acumulado por décadas de cada categoría.
Evaluación de las viviendas patrimoniales en el AMM

A continuación buscaremos describir y evaluar el conjunto de bienes identificados como viviendas (como tipología funcional originaria) a partir del análisis de algunas de las variables relevadas más significativas, lo que nos permitirá conocer las especificidades de este tipo de obras y sus posibilidades de conservación en el marco de diferentes propuestas. Los gráficos que se muestran son solo los del área metropolitana de Mendoza (AMM) aunque también se procesaron (con elaboración de gráficos) los datos discriminados en cada uno de los seis departamentos, de este modo se permitió la comparación entre ellos y con la media del AMM. Se desarrolla el análisis siguiendo el orden de las variables:

\section{Relación uso original y actual $P^{5}$}

En el conjunto del patrimonio relevado en el AMM (1 030 edificios), tanto en el uso original como en el actual existe un predominio de la función residencial (57\% original, 40\% actual). Es decir, casi el 60\% de los edificios del patrimonio arquitectónico actual del AMM fueron en su origen viviendas y el 40\% sigue manteniendo ese uso (Figuras 5 y 6).

El departamento con mayor presencia de viviendas en su patrimonio es Godoy Cruz, por cuanto a partir de la modernización de fines del siglo XIX fue perdiendo territorio dedicado a la agroindustria vitivinícola (que crecía hacia el sur) y fue paulatinamente absorbiendo la función residencial de la ciudad hasta fines del siglo XX.

Si comparamos el uso original con el actual podemos advertir que en promedio una de cada tres viviendas ha perdido su función originaria (Figura 6). Sin embargo, esta relación varía según la ubicación del edificio en el AMM: en Capital dos de cada tres viviendas han perdido su uso original, mientras que en Guaymallén el 85\% de las viviendas conservan su uso, esto quiere decir que solamente el 15\% ha perdido el uso residencial. Esto se explica en las características del patrimonio capitalino, con predominio de grandes residencias, que han sido convertidas al uso institucional o comercial. Las casas de patios, propias del periodo de la gran inmigración de principios del siglo $\mathrm{XX}$ prácticamente han desaparecido por el reemplazo edilicio. El resto de los departamentos mantiene valores próximos a los de Guaymallén, y en toda el AMM se verifica la hipótesis de que tanto la ubicación como las dimensiones de los edificios han incidido en el mantenimiento del uso habitacional o el cambio de uso a público o comercial, es decir, tanto las viviendas más grandes como las ubicadas en áreas centrales no mantuvieron, por lo general, el uso residencial.

En los ejemplos presentados puede observarse cómo las grandes residencias urbanas se encuentran en mayor cantidad de casos ya sea con nuevos usos (Figura 7) o desocupadas, sin uso (Figura 8), mientras que las viviendas de menores dimensiones y categoría, en áreas suburbanas (Figura 9) o en áreas rurales (Figura 10) logran mantener el uso y su vigencia funcional. El cambio de uso también tiene vinculación con otras variables analizadas como el tipo de propiedad y la valorización que el depositario manifiesta de la propiedad. Las viviendas que han logrado mantener el uso se mantienen en propiedad de sus dueños desde generaciones anteriores, mientras que las grandes viviendas que cambiaron el uso han sido adquiridas o alquiladas por instituciones o empresas.

\section{Relación uso original / datación ${ }^{6}$}

Si vinculamos el uso original de los edificios patrimoniales del AMM y la fecha en que fueron 


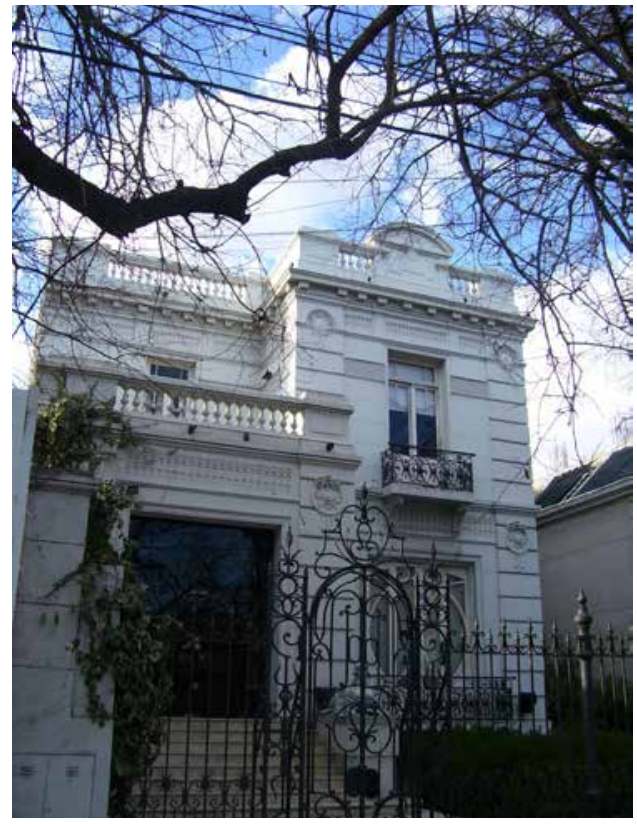

construidos, podemos advertir que cada agrupamiento tipológico respecto del uso tiene una curva particular que revela los aspectos significativos del proceso histórico en relación con esa porción de la producción arquitectónica del período. Es decir, que la situación varía si se trata de bodegas o viviendas, de edificios del equipamiento público o del comercio (Figura 7).

El conjunto de las viviendas hoy consideradas patrimoniales tienen una curva ascendente con un notorio pico hacia 1910 (en el AMM en general, ver Figura 11) con un dispersión en los departamentos que va desde 1900 (Godoy Cruz) a 1915 (Capital, Guaymallén).

En Luján y Maipú el uso residencial tiene una curva ascendente con un notorio pico hacia 1910, época del cenit de la modernización y la expansión vitivinícola hacia el sur, y conforma un patrimonio valioso compuesto en gran medida por las casas patronales de los establecimientos de las bodegas (Figura 15). En ambos departamentos también se registra otro pico hacia 1940 con los chalets "modernos" de las antiguas bodegas (Figuras 18 y 19).

En Guaymallén, hacia el este, el uso residencial es el agrupamiento que comprende el mayor número de bienes y el que más ha mantenido su uso, la curva se inicia en el siglo XIX y tiene su pico máximo entre los años 1910 y 1925 (Figuras 14 y 16). Representa una situación intermedia entre los ejemplos más antiguos del norte del AMM (Las Heras) y el sur de la expansión vitivinícola (Luján y Maipú).

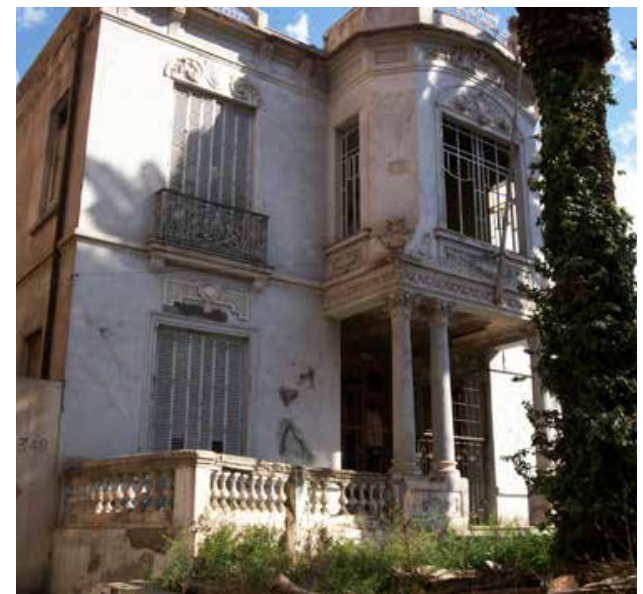

Figura 7:

Casa Pelicciari, Capital (nuevo uso: hoy Instituto Zaldívar).

Fuente:

Proyecto PICT 13

- 14022, dirigido por Silvia Cirvini

Figura 8:

Casa Stoppel,

Capital (sin uso).

Fuente:

Proyecto PICT 13

- 14022, dirigido por Silvia Cirvini

En Las Heras el uso residencial comprende el mayor número de bienes. Tiene una curva ascendente que nace tempranamente en el siglo $\mathrm{XIX}$, con un notable incremento hacia $1890 \mathrm{y}$ un máximo absoluto hacia 1910; en 1920 tiene un mínimo relativo y vuelve a ascender hacia 1930. Esta curva pone en evidencia el temprano desarrollo de Las Heras como parte de la histórica de Ciudad de Mendoza hasta el siglo XIX, y el progresivo desplazamiento de la función residencial

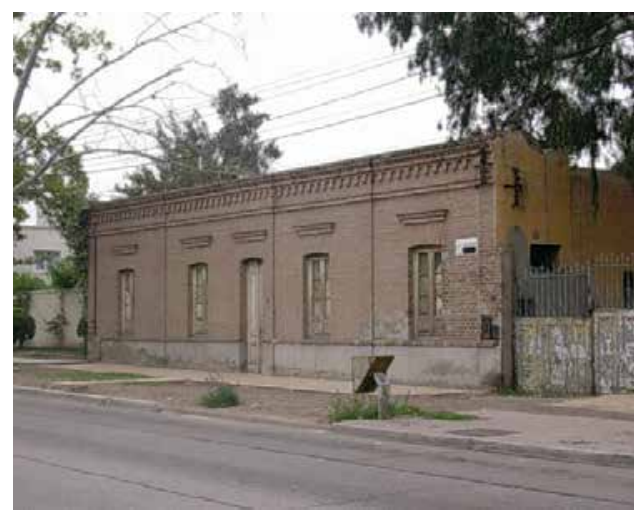

Figura 9:

Vivienda en Bermejo,

Guaymallén

(conserva uso).

Fuente:

Proyecto PICT 13

- 14022, dirigido

por Silvia Cirvini

Figura 10:

Vivienda en El

Sauce, Guaymallén

(conserva uso).

Fuente:

Proyecto PICT 13

- 14022, dirigido

por Silvia Cirvini

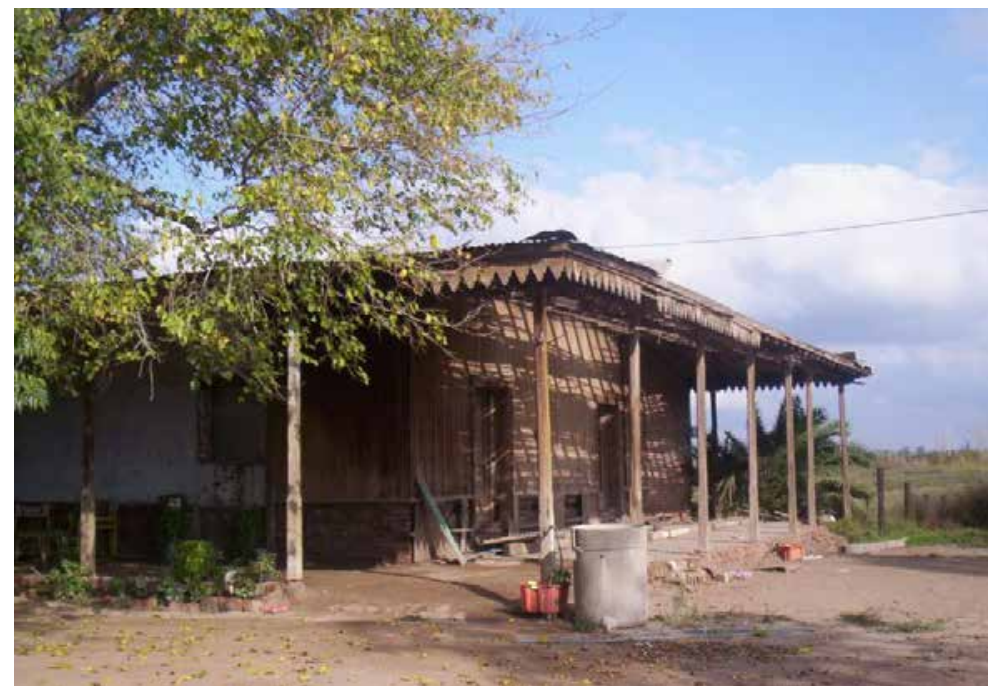




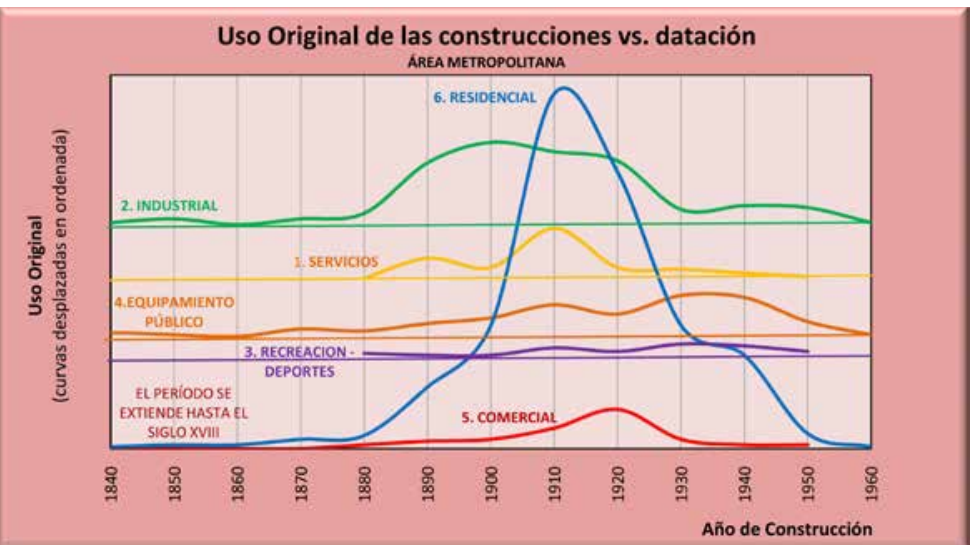
Casa rural en $L a$ Cieneguita, Las Heras (1880).

Fuente:

Proyecto PICT 13 - 14022 dirigido por Silvia Cirvini

Figura 13: Casa patronal Bodega Panquehua, Las Heras (1864).

Fuente:

Proyecto PICT 13 - 14022 dirigido

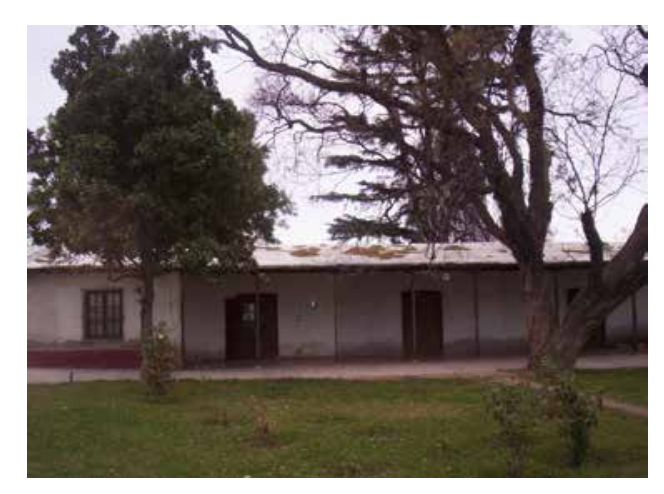
por Silvia Cirvini

7. Metadata: Uso original: ver nota 5 . Estilo arquitectónico: se considera el estilo como resultado de tres elementos: a) Composición (pondera e orden que adopta la configuración ola estructuración espacial), b) Proporción (disposición, conformidad o correspondencia debida entre las partes) y c) Decoración y ornamentación (lenguajes o repertorios formales en los elementos ornamentales y decorativos). Se definieron para la arquitectura regional 13 categorías posibles: A. Poscolonial (1820/1850), B. Vernácula siglo XIX (1850/1900),

C. Vernácula, siglo XX (1900/1950), D. Neoclásico tardío (1861/1910), E. Academicismo francés (1880/1930), F. Eclecticis con una combinación de lo urbano y lo industrial cuyo patrimonio testimonia la evolución de la región y la mixtura estilística (Figura 20). Finalmente, el departamento de Capital posee un importante patrimonio público que comprende grandes edificios urbanos (bancos, comercios, clubes, escuelas, etc.) con un abanico de estilos y tipologías arquitectónicas y también importantes conjuntos como el centro cívico, el cementerio o los principales espacios verdes (Parque San Martín y plazas) donde el patrimonio arquitectónico vinculado produce una sinergia con cada sitio en cuanto a sus posibilidades como recurso.

La relación entre el uso (tipo funcional) y el estilo (tipo formal) nos ha permitido analizar las particularidades o especificidades de cada agrupamiento respecto de lo morfológico y lo estético, que es precisamente la variable más reconocida por un público no experto. Las bodegas del siglo XIX son predominantemente neoclásicas y también sus viviendas patronales. Hacia el Centenario de la Independencia (mayo de 1910) aparecen los nuevos lenguajes del modernismo (floréale y art nouveau) en las viviendas (Figura 20) mientras que las bodegas siguen siendo clásicas.

En Capital la clasificación de las viviendas según corrientes estilisticas corrobora las características del conjunto del patrimonio arquitectónico capitalino: están presentes todas las corrientes desarrolladas a lo largo del período. La ciudad muestra un abanico de variantes estilísticas único en el AMM. Sin embargo, existen elocuentes ausencias: son casi inexistentes las corrientes vernáculas, de las que solo quedan ejemplos aislados, situación que se explica en el reemplazo edilicio sostenido y las exigentes normas de construcción de Capital que terminaron tanto con sistemas y tecnologías de tierra cruda como con las construcciones de madera.

En general, el patrimonio que conserva la ciudad actual corresponde a una arquitectura urbana de muy buena calidad constructiva con materiales y sistemas perdurables, realizada siempre con mediación profesional. Las cuatro corrientes estilísticas mayoritarias que poseen un porcentaje equivalente (15\% cada una) son: neoclásico tardío, eclecticismo, neocolonial y modernismo.

En las viviendas predomina el modernismo (Figura 21), con un pico hacia 1910, luego le sigue el neoclásico tardío (italianizante) que representan las viviendas más antiguas asocia- 


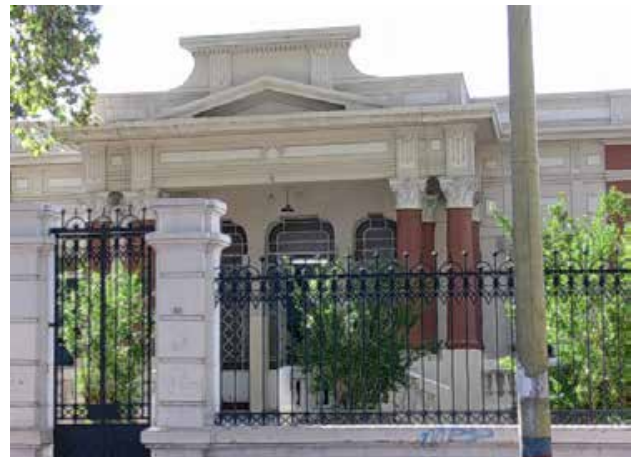

das a la inmigración (Figura 17) y el neocolonial como expresión de la vivienda moderna de los años veinte y treinta (Figura 22).

En Godoy Cruz, dentro del agrupamiento de las viviendas, que representa el grueso de los bienes patrimoniales, predominan tres corrientes estilísticas: el neoclásico tardío, el pintoresquismo y el neocolonial. Son escasos, en cambio, los ejemplos de arquitectura vernácula por el reemplazo edilicio importante que ha tenido el departamento en su parque habitacional.

En Maipú, en los dos agrupamientos de uso más importantes: el residencial y el industrial, hay una presencia muy importante de las corrientes vernáculas y del neoclásico tardío por la importancia del patrimonio vitivinícola. En el uso residencial aparecen también otras corrientes estilísticas, como el pintoresquismo (Figura 24) con una distribución equilibrada que evidencia su construcción a lo largo de todo el período.

En Guaymallén, en el agrupamiento de uso original residencial, que representa el grueso de los bienes patrimoniales, predominan dos corrientes estilísticas: la arquitectura vernácula del siglo XX (Figura 26) y el pintoresquismo (Figura 23). Sigue en importancia el neoclásico tardío, y luego, las otras corrientes distribuidas de manera similar. Esto pone en evidencia el peso de la arquitectura rural en particular los chalets de las bodegas.

En Luján pudimos verificar, como en Maipú, que en los dos agrupamientos de uso más importantes: residencial e industrial, hay una presencia muy importante de las corrientes vernáculas (siglos XIX y XX) y del neoclásico tardío (Figura 25), lo que alude al peso del patrimonio vitivinícola (sumados representan el 67\% del total). Otras corrientes estilísticas significativas en Luján son el pintoresquismo y el neocolonial, asociados a la arquitectura de los chalets de los años veinte al cuarenta.
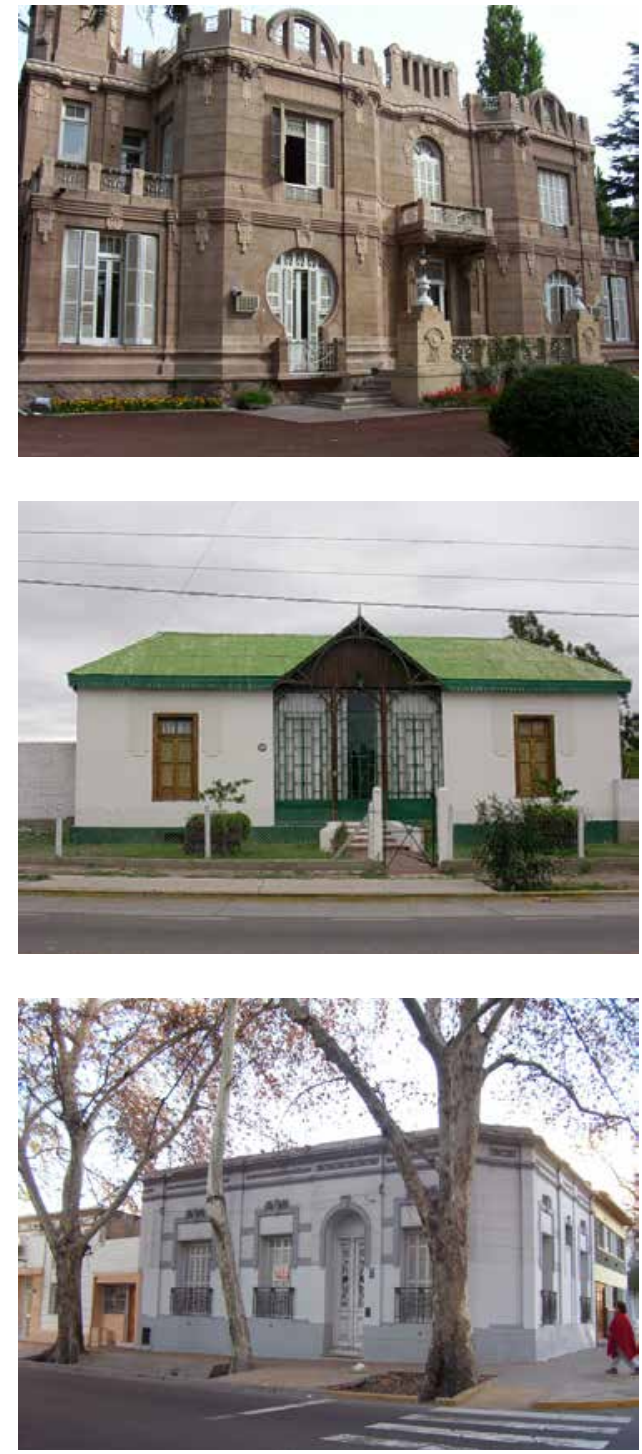

Las Heras es el único departamento dentro del área metropolitana donde es predominante la arquitectura vernácula, en sus tres vertientes: poscolonial, siglo XIX y siglo XX, tanto en el agrupamiento residencial como en el industrial. Esto se explica básicamente por dos causas: un desarrollo temprano de este departamento como suburbio de la ciudad y el relativo estancamiento que tuvo durante el siglo XX respecto del próspero sur, hacia donde se expandió la superficie cultivada del oasis, lo cual trajo aparejado un menor recambio edilicio.

\section{Relación forma de la planta/ datación ${ }^{8}$}

La relación entre formas de las plantas y datación en las viviendas del período permite advertir los cambios tipológicos en la morfología y conformación espacial que fueron transitando estas
Figura 14:

Casa urbana en San José, Guaymallén (1925).

Fuente:

Proyecto PICT 13

- 14022, dirigido

por Silvia Cirvini

Figura 15:

Chalet Gargantini,

Maipú (1910).

Fuente:

Proyecto PICT 13

- 14022, dirigido

por Silvia Cirvini

Figura 16:

Casa Bodega Reyter, Guaymallén (1890).

Fuente:

Proyecto PICT 13

- 14022, dirigido por Silvia Cirvini

\section{Figura 17:}

Casa urbana en

calle Montevideo,

Capital (1910).

Fuente:

Proyecto PICT 13

- 14022, dirigido

por Silvia Cirvini

mo (1880/1930), G. Historicismo (1880/1930), H. Pintoresquismo (1900/1955),

I. Neocolonial (1920/1950),

J. Modernismo

(1900/1920), K. Art decó

(1925/1950), L. Neoacademicismo (1940/1955) y M. Racionalismo (1930/1950).

\section{Metadata:}

Forma de la planta: se entiende por "forma" el contorno o silueta que describe

la superficie cubierta de la planta baja. Las categorías definidas fueron: 1. Cuadrada, sin patio interior, 2. Cuadrada, con patio interior, 3. Rectangular, sin patio, 4. Rectangular, con patio, 5 . Rectangular, con patios, 6 . En “L”, 7. En “T”, 8. En “U”, 9. En "I" o H, 10. Compacta regular, 1. Compacta irregular, 12. Dispersa y 13. Otra. Datación: Ver nota 6. 

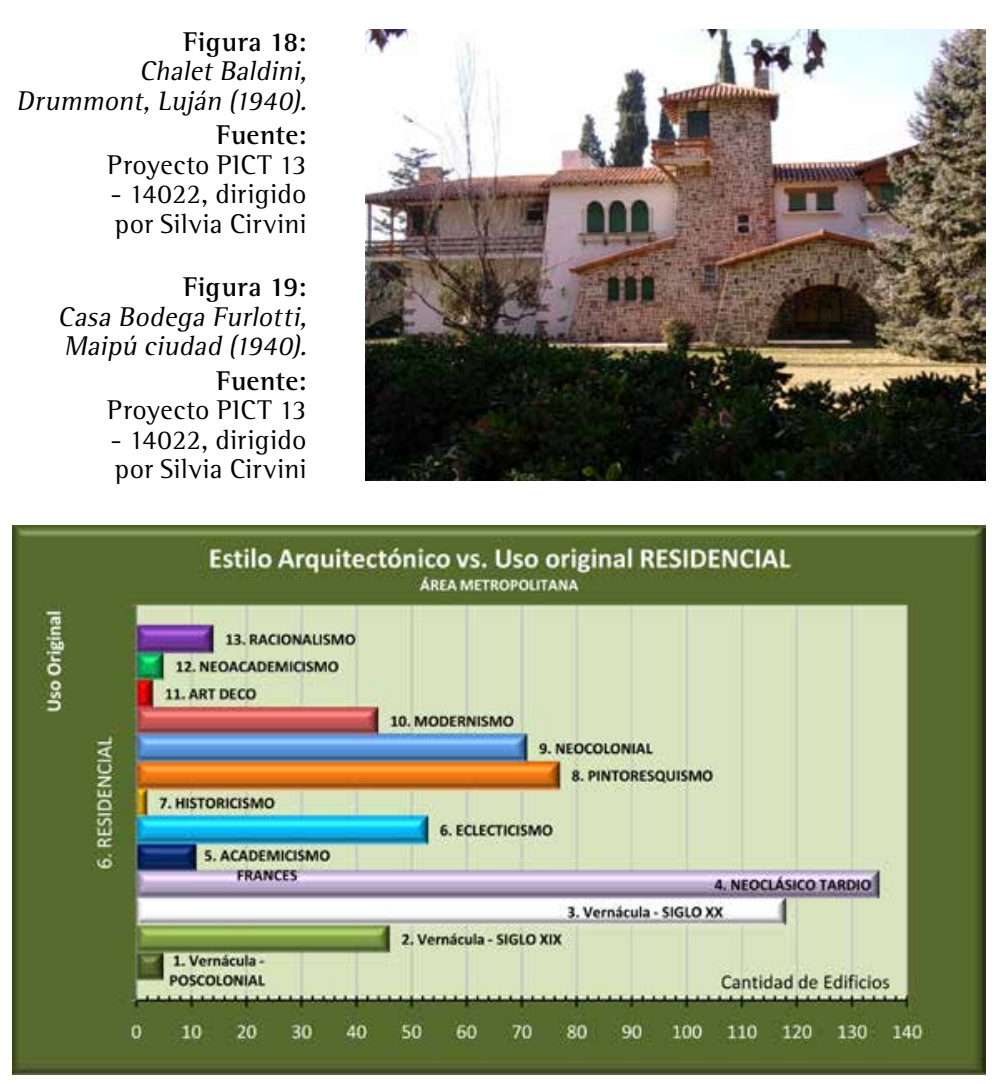

Figura 20: Área metropolitana. Corrientes estilísticas en la arquitectura

residencial.

Fuente:

Silvia Cirvini

Figura 21:

Casa Baquero Suárez (modernismo), Capital (1912).

Fuente:

Proyecto PICT 13 - 14022, dirigido por Silvia Cirvini

Figura 22: Casa López Frugoni (neocolonial), Capital (1927).

Fuente: Proyecto PICT 13 - 14022, dirigido por Silvia Cirvini

9. Los tipos identificados de vivienda popular colectiva son: la "casa de vecindad" que es una serie de unidades habitacionales independientes (de una o dos plantas) organizadas sobre una circulación (pasillo solo peatonal) que puede ser central o lateral.

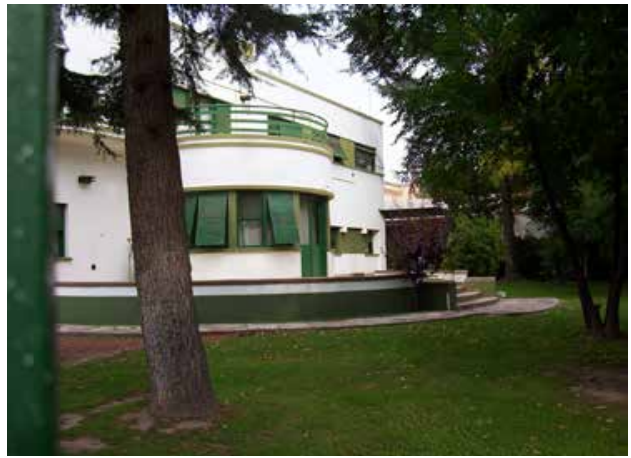

tablecerse vínculos entre las formas de las plantas y los tipos estilísticos predominantes. Mientras las casas de patios y las plantas articuladas con galerias se vinculan a la arquitectura vernácula, las casas en hilera (de patio lateral) y las de planta en "H" y "U”, con el neoclásico tardío de la inmigración, así como las plantas irregulares $\mathrm{y}$ asimétricas son propias del pintoresquismo y el neocolonial.

Veamos por departamento, cuales son las particularidades observadas:

En Capital predominan las plantas compactas regulares en áreas centrales (por una ocupación intensiva del suelo) o francamente irregulares (chalets en áreas residenciales). Son muy escasas las viviendas de plantas articuladas, en "L", en "H" y en "U”, propias de las viviendas suburbanas y rurales. En el departamento capitalino ha desaparecido un tipo muy difundido entre el patrimonio doméstico: las casas en hilera, de patio lateral, propias de la inmigración que existían en gran número hace 30 años, constituían áreas homogéneas de la ciudad y hoy son solo ejemplos aislados. También han desaparecido las casas de planta cuadrada o rectangular con patios, que ocupaban importantes lotes urbanos y que fueron blancos del reemplazo edilicio para la edificación en altura. Quedan escasos testimonios de la vivienda colectiva popular que responden al tipo "casas de vecindad" mientras que desaparecieron los tradicionales “conventillos”, aunque perdura un sucedáneo de esta tipología como son las “pensiones" instaladas en antiguas casas ${ }^{9}$. En Capital se encuentran los escasos ejemplos patrimoniales de edificios de departamentos, ya que, en el AMM en su conjunto, la gran mayoría de las viviendas patrimoniales catalogadas son individuales, de una o dos plantas.

En Godoy Cruz las formas de las plantas de las viviendas tienen estrecha relación con las ti- 


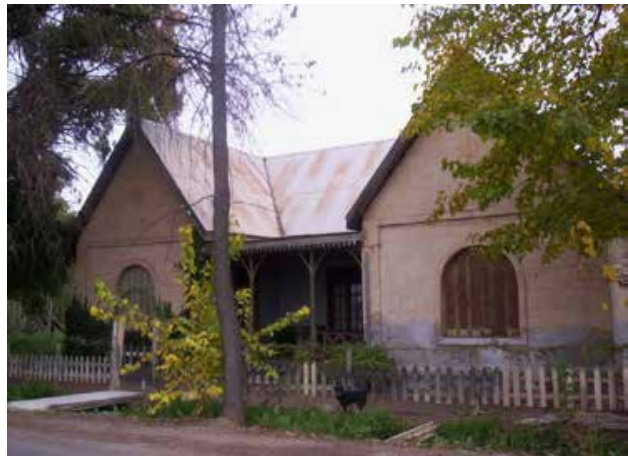

pologías funcionales predominantes. Las plantas compactas irregulares (30\%) y regulares (10\%) corresponden a las viviendas tipo chalets, las plantas en "L" (20\%) corresponden a la tradicional casa en hilera, con patio lateral, tipología propia de la inmigración. La planta compacta irregular presenta una curva con dos picos en coincidencia con dos momentos de auge de la construcción de chalets, el primero hacia 1920 (pintoresquismo) y el segundo hacia 1940 (neocolonial californiano). Las plantas en "L" (neoclásico tardío - italianizante) corresponden a la vivienda urbana del tipo en hilera y tienen un máximo absoluto hacia 1910 con el crecimiento del flujo inmigratorio. Las plantas en " $\mathrm{U}$ " y en " $\mathrm{H}$ " tienen su pico hacia 1900 y decrecen hacia el Centenario por cuanto se relacionan con las villas suburbanas de antiguas bodegas desaparecidas por la urbanización creciente del departamento y el desplazamiento de la actividad agrícola hacia el sur.

Entre los bienes de Maipú existe un predominio de plantas rectangulares (por la gran cantidad de bodegas), luego le siguen en importancia la planta compacta irregular y las plantas en "l". Estas tendencias generales para todo el patrimonio de Maipú se mantienen en el agrupamiento de uso residencial, donde las plantas regulares son mayoría con predominio de rectangulares y cuadradas. La relación entre formas de plantas y datación en las viviendas del período permite advertir los cambios tipológicos en la morfología y conformación espacial que estas obras fueron transitando. En el primer pico de la producción de viviendas, hacia 1890, hay una vivienda en "L" por cada tres de planta rectangular. En el segundo pico (1910), si bien siguen creciendo las plantas rectangulares, aparecen y se consolidan las plantas en "U", la cuadrada y la irregular. Estas variaciones aluden a la transición de los modelos vernáculos del siglo XIX a las viviendas tipo chalet o villa del Centenario.
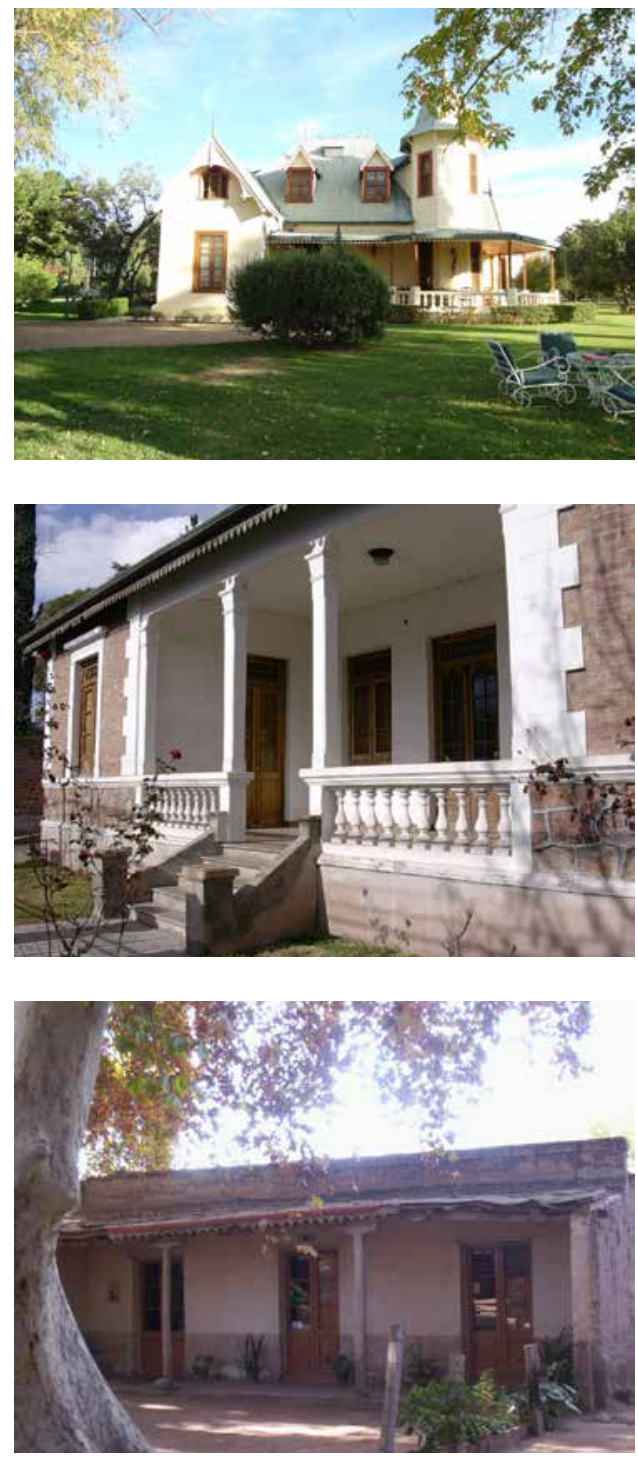

Figura 25:

Casa Bodega Calle (neoclásico tardío), Luján (1912).

Fuente:

Proyecto PICT 13

- 14022, dirigido

por Silvia Cirvini

Figura 26:

Casa en El Bermejo (vernácula siglo $X X)$, Guaymallén (1920).

Fuente:

Proyecto PICT 13

- 14022, dirigido por Silvia Cirvini

En Luján, un tercio de las viviendas tienen plantas compactas irregulares (chalets), otro tercio corresponde a las plantas en " $\mathrm{l}$ " y en " $\mathrm{U}$ " (variantes de la casa de patios o en hilera) y el tercio restante agrupa las otras formas de planta, con predominio de la compacta regular (9\%). La relación entre formas de plantas y datación en las viviendas del período permite advertir los cambios tipológicos en la morfología y conformación espacial que estas obras fueron transitando. En el primer pico de la producción de viviendas hacia 1890 hay plantas en "U", en "L" y planta rectangular. En el segundo pico (1910) se registra el máximo absoluto de las plantas en "L", las plantas rectangulares y las compactas regulares. Estas variaciones aluden a la transición de los modelos vernáculos del siglo XIX a las viviendas tipo chalet o villa del Centenario. La curva de las viviendas de planta compacta irregular, si bien
El "conventillo", prácticamente desaparecido, era básicamente una vivienda (generalmente una "casa de patios") donde a cada familia le correspondía una habitación y los servicios (cocina, baños y lavandería) eran compartidos, así como el patio y las galerías. Finalmente las "pensiones", que surgen en el siglo XX como alternativa de alojamiento a personas no pertenecientes al ámbito familiar ya fuera con el alquiler 0 elsubalquiler de piezas o sectores de la casa, que en el presente han vuelto a surgir como una alternativa de uso rentable de grandes viviendas urbanas. 
Figura 27:

Casa Bodega La Germania, en Godoy Cruz, planta en " $U$ ". Fuente:

Proyecto PICT 13 - 14022, dirigido por Silvia Cirvini

Figura 28: Villa Constanza, en Maipú, planta en " $H$ ". Fuente:

Proyecto PICT 13 - 14022, dirigido por Silvia Cirvini

Figura 29: Casa en Guaymallén, cuadrada sin patio, con galerías.

Fuente:

Proyecto PICT 13 - 14022, dirigido por Silvia Cirvini

Figura 30 Casa Guevara Arenas, en Maipú, rectangular con patio. Fuente: Proyecto PICT 13 - 14022, dirigido por Silvia Cirvini
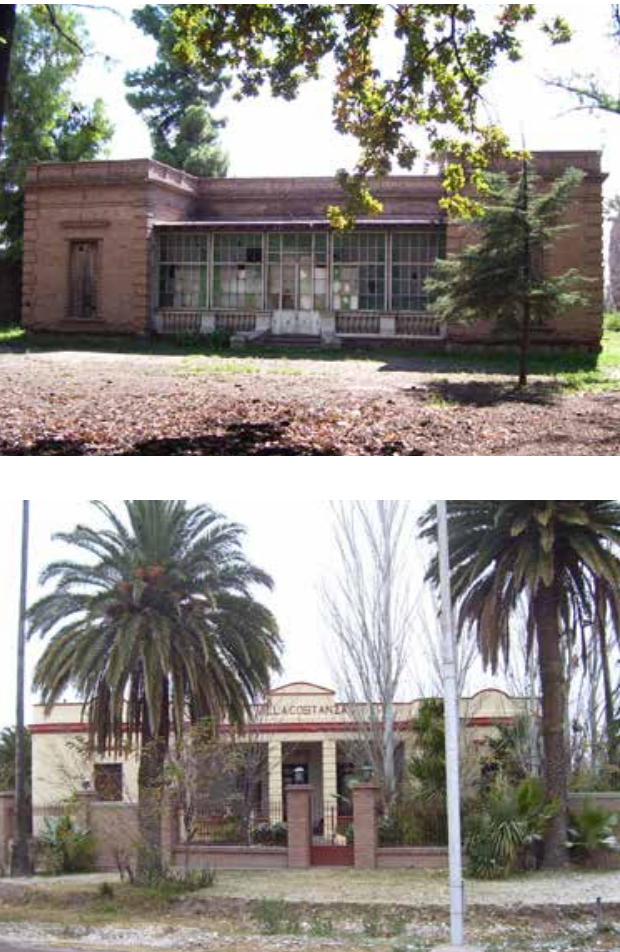

se inicia en el siglo XIX, se halla desplazada en el tiempo respecto de la producción en general y tiene su máximo absoluto hacia 1930, por la presencia de los chalets pintoresquistas y neocoloniales (Figuras 31 y 32).

En las viviendas patrimoniales de Guaymallén, las plantas rectangulares son la tercera parte del total, le siguen las plantas en "U" con el 20\%,
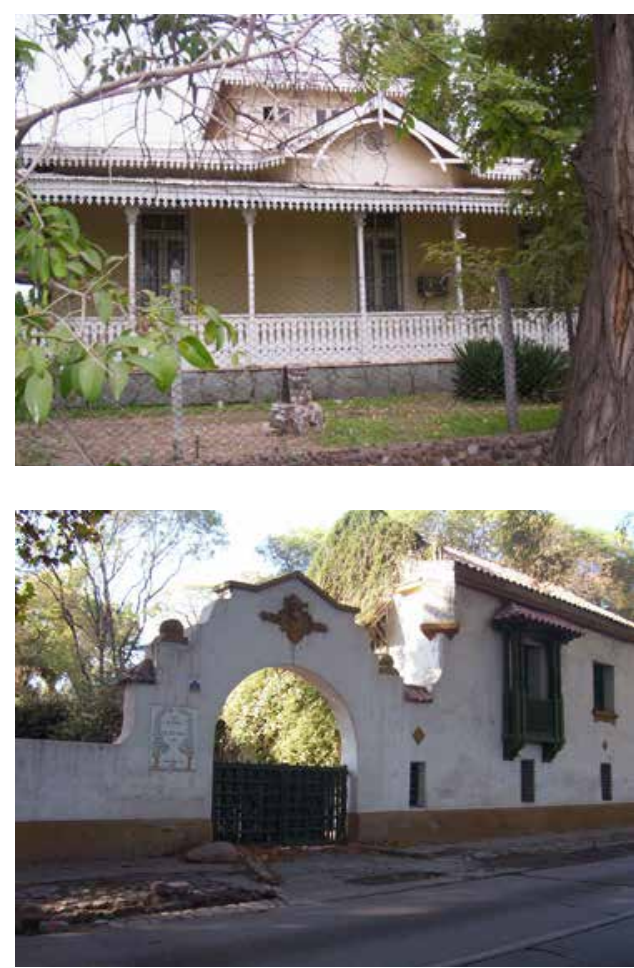

luego en "L" y cuadradas con el 15\% cada una. El tipo de plantas que encontramos en este departamento se corresponde con la difusión del chalet rural de planta compacta con galerías perimetrales, tanto dentro de las corrientes vernáculas como pintoresquistas. Las plantas cuadradas, en "L" y en "U" se encuentran vinculadas con la arquitectura de las viviendas rurales y tienen un desarrollo temprano en Guaymallén, con pico hacia 1910, mientras que las de planta rectangular (asociada a viviendas del crecimiento de áreas urbanas) tienen un máximo hacia 1920. Las plantas compactas, irregulares y rodeadas con jardines (de los chalets californianos) se desplazan hacia las décadas de los años treinta, cuarenta y cincuenta.

La planta en "L" abarca un amplio espectro de soluciones estilísticas y formales, de acuerdo con su ubicación y las dimensiones de los lotes (comparar la culta casa urbana en lote angosto de la Figura 33 con la tradicional solución vernácula de los amplios terrenos de los suburbios de Figura 34).

En Las Heras, en las viviendas patrimoniales las plantas en "L" $(39,5 \%)$ son mayoría y les siguen las rectangulares (29\%). Las plantas en " $\mathrm{H}$ " y compactas de los chalets son escasas en este departamento, ya que corresponden a tipos desarrollados con la modernización vitivinícola del siglo $\mathrm{XX}$, desplazada hacia el sur (Maipú y Luján, Figuras 31 y 32 , respectivamente). La relación entre formas de plantas y datación en las viviendas del período permite advertir los cambios tipológicos en la morfología y conformación espacial que estas obras del patrimonio doméstico fueron transitando. Las plantas en "L" de la arquitectura vernácula se desarrollan a lo largo de todo el período con picos hacia 1850, 1885 y 1930, mientras que las viviendas de plantas rectangulares están concentradas en un período más breve (1890-1930) con un pico en la curva hacia 1910. El patrimonio doméstico posee en Las Heras tipologías casi desaparecidas en el resto del AMM, como las pertenecientes a la arquitectura vernácula del siglo XIX.

Evaluación de otras variables analizadas: estado general, número de pisos, material de fachada, ubicación, etc.

Es significativo señalar que un altísimo porcentaje de los ejemplos de bienes evaluados dentro del conjunto de viviendas patrimoniales catalogadas corresponden a lo que podemos llamar vivienda 
individual aislada, construida en propiedades rurales (agrícolas o agroindustriales vitivinícolas) o en lotes urbanos o suburbanos. Los ejemplos patrimoniales de vivienda colectiva son escasos en el área metropolitana de Mendoza: corresponden a la producción de barrios para obreros y empleados (sectores medios y populares) que se inician con las "Casas colectivas" (1935) y continúan con los barrios de chalecitos californianos (1946-1955), construidos en el primer peronismo. En estos casos predomina un valor de conjunto que caracteriza un paisaje urbano por sobre la evaluación de cada unidad de vivienda (en los barrios "peronistas" muy modificadas).

Veamos cómo la evaluación de otras variables relevadas contribuye a caracterizar este conjunto de bienes y a ponderar su valoración como recurso. Las viviendas patrimoniales cuentan con componentes arquitectónicos desaparecidos en los programas de lo que podemos llamar la "casa moderna” (desarrollada a partir de 1950 y generalizada desde los años sesenta en adelante): el 54\% de las viviendas evaluadas tienen galerías, y en más del 17\% hemos podido registrar la presencia de sótanos, subsuelos o entresuelos. Los cambios en las formas del habitar, por una parte, con el agregado de instalaciones y elementos de confort y la reducción de las superficies cubiertas, fueron las razones básicas de estas pérdidas. Tanto las galerías como los sótanos hacían de estos edificios buenos modelos de adaptación bioclimática ${ }^{10}$.

También es significativo señalar, respecto de la altura de los edificios, que en el conjunto de bienes evaluado el $66 \%$ de las viviendas tienen solo planta baja, un 31\% tiene además un piso superior y solo el 3\% tiene dos o más pisos superiores. El predominio de edificación baja es común a todo el patrimonio de la región, indicador también de la adecuación a la condición sísmica y a una relación armónica entre edificios y vegetación. El patrimonio de las viviendas está constituido en particular por viviendas de una planta, a lo sumo con un primer piso o torres y miradores, ubicadas por lo general en determinados barrios urbanos, suburbios o zonas agrícolas.

En cuanto a los materiales empleados, casi el $60 \%$ de las viviendas catalogadas tienen su fachada de ladrillo cocido, solo una de cada tres viviendas tiene fachada de adobes. Esta condición es relevante en cuanto el adobe es material prohibido en la reglamentación de construcción en el AMM y es mucho más difícil conservar
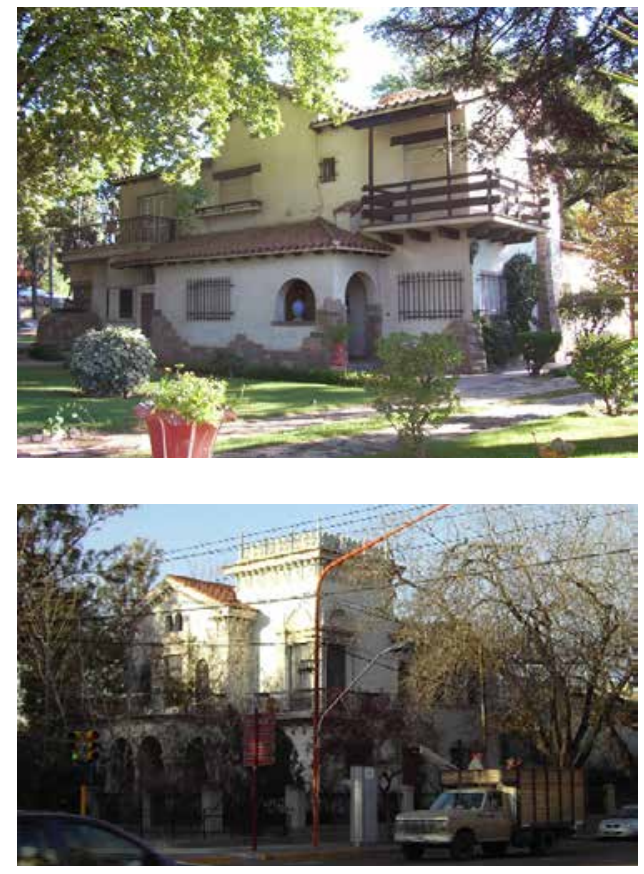

Figura 31:

Chalet suburbano en Maipú, planta compacta irregular. Fuente:

Proyecto PICT 13

- 14022, dirigido por Silvia Cirvini

Figura 32:

Casa Arenas (chalet urbano) en Capital, compacta irregular. Fuente:

Proyecto PICT 13

- 14022, dirigido por Silvia Cirvini
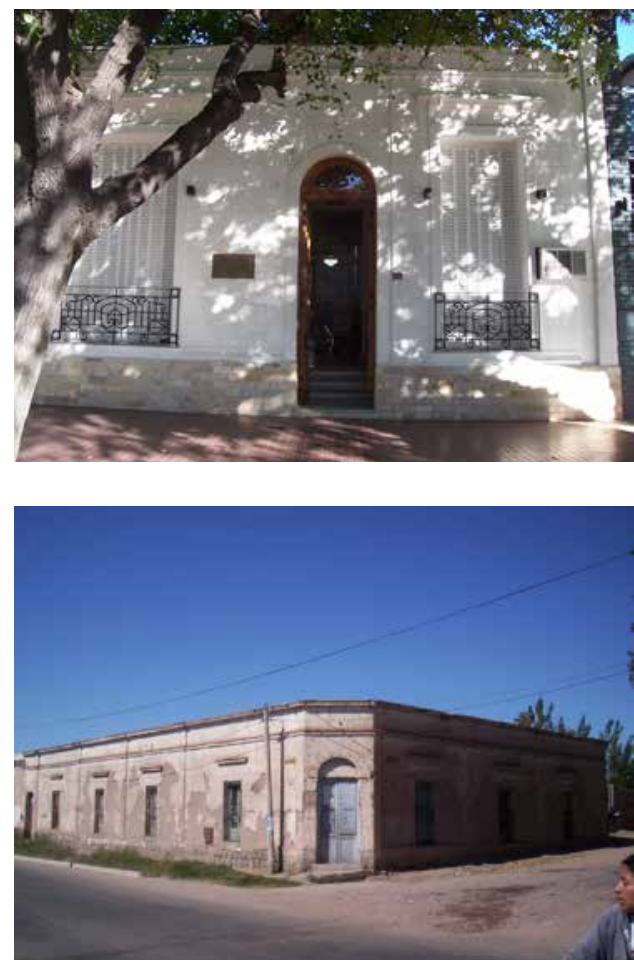

Figura 33:

Casa urbana en Godoy Cruz, planta en "L", con patio.

Fuente:

Proyecto PICT 13

- 14022, dirigido por Silvia Cirvini

Figura 34:

Casa suburbana en Guaymallén, planta en " $L$ ", con galería.

Fuente:

Proyecto PICT 13

- 14022, dirigido por Silvia Cirvini

bienes de los sistemas de tierra cruda por la severidad de los códigos. Podemos afirmar, a partir del conocimiento de la arquitectura regional, que los edificios construidos en tierra cruda tienden a desaparecer, en particular en zonas urbanas, principalmente por los obstáculos que presenta la reglamentación sismorresistente a su conservación. Con el ladrillo cocido, en cambio, se admiten diferentes "mejoras" de su capacidad portante, ya sea verificando la eficacia de la estructura
10. Tanto las galerías, que servían como espacio de transición entre el interior y los patios y eran utilizadas para estar y trabajar durante el día, como los sótanos, protegidos de la luz y el calor para conservar todo tipo de mercaderías y productos de fabricación casera, eran componentes muy adaptados al clima semidesértico y mediterráneo de Mendoza. 
muraría (en ocasiones se trata de mamposterías armadas) o adicionando estructura de $\mathrm{H}^{\circ} \mathrm{A}^{\circ}$ (hormigón armado).

El 75\% de las viviendas se encuentra en buen estado de conservación ${ }^{11}$, derivados de un uso actual adecuado y de un mantenimiento periódico. En el 25\% restante, tres son las razones principales que atentan contra la integridad y conservación de los edificios: 1) estar desocupado sin uso, si esta situación se prolonga es, en la mayoría de los casos, antesala de la demolición (10\% de las viviendas está sin uso en el presente), 2) un destino actual inapropiado para el edificio, que impone transformaciones agresivas e irreversibles, con pérdida del significado cultural, la integridad y la autenticidad del bien, y 3) la usurpación o uso ilegal del bien, generalmente como vivienda, porque implica una sobreocupación, el mal uso del edificio y un nulo mantenimiento. Dentro del conjunto de viviendas patrimoniales evaluado solo un 14\% tiene un uso inapropiado en la actualidad (la quinta parte de este porcentaje corresponde a viviendas usurpadas ${ }^{12}$.

En relación con el emplazamiento de las obras, pudimos corroborar que la ubicación suburbana y rural favoreció la conservación de un importante conjunto de viviendas como las asociadas a la vitivinicultura y las que formaban parte de los conjuntos ferroviarios. Las viviendas emplazadas dentro de la traza urbana sufren una mayor presión del mercado inmobiliario y van siendo reemplazadas en gran número. Otro factor que incide favorablemente en la conservación de estos bienes ha sido la pertenencia a empresas productivas, comerciales o ferroviarias, ya fueran estatales o privadas. Sin embargo, no todo este patrimonio ha tenido la misma suerte: mientras la industria vitivinícola ha logrado superar la crisis de reconversión de las últimas décadas del siglo $\mathrm{XX}$ sin perder su patrimonio histórico (conservado al menos parcialmente), las viviendas del sistema ferroviario han padecido, primero, la falta de uso, luego, la usurpación, y en algunos casos hasta desmantelamiento por el cierre y abandono del sistema ferroviario. Esta situación confirma que tras de la pérdida del patrimonio cultural subyace siempre un problema económico social, una crisis que impacta en lo ambiental y cuya resolución y manejo está ligada al modelo de desarrollo vigente.

\section{Conclusiones}

El patrimonio de las viviendas representa un conjunto de gran valor potencial como recurso cultural, como referente de memoria social que, sin embargo, es poco reconocido por gran parte de los propietarios o depositarios, los poderes públicos y la sociedad en general.

En primer lugar, el trabajo realizado permite corroborar el valor y la importancia de este conjunto de obras dentro del patrimonio arquitectónico regional, es decir, la valoración de las viviendas como producto cultural. Como puede advertirse en el desarrollo y análisis de este tipo de edificios, este patrimonio es muy importante en volumen, variedad morfológica y tipológica y permite mostrar la notable riqueza de los diversos componentes de los modos del habitar con fenómenos más amplios como la construcción del espacio territorial y urbano, y sus vínculos con el desarrollo económico del oasis (en particular la vitivinicultura como agroindustria). Como ningún otro agrupamiento tipológico, las viviendas muestran un abanico de soluciones, desde las más modestas y populares hasta las más sofisticadas y lujosas, con un espectro de materiales y tecnologías que evidencian la búsqueda de mejores respuestas ante los sismos, su ubicación en el medio rural y el urbano, su construcción en materiales y sistemas vernáculos (tapia, adobe y quincha) o en modernos, como el hormigón armado, el acero y las mamposterías armadas.

En segundo lugar, las viviendas representan un patrimonio de alto valor simbólico porque, como ningún otro tipo de edificios, la casa es el lugar de lo privado, lo cotidiano, el escenario más cercano a la vida de todos los días de hombres y mujeres de otros tiempos. Dice Dyna Guitián (2007):

La carga simbólica de la vivienda trasciende el concepto de albergue para convertirse en hogar, el lugar para la producción de los afectos, de los proyectos, de las rupturas y las despedidas; el lugar de lo íntimo, de lo individual, de las relaciones sociales básicas. La vivienda es el lugar de la historia de la familia.

Las viviendas, dentro del patrimonio arquitectónico, son referentes de la memoria intra e inter grupal y, a la vez, inter generacional: una herramienta disponible y cercana de aprendizaje y conocimiento del pasado contado por la expe-
Fejemplo en su mayoría usurpadas. 
riencia vivida de los padres, los abuelos y hasta los bisabuelos (cada vez más frecuente con el aumento de la expectativa de vida).

En relación con su potencial valor como recurso, toda vivienda es fácilmente aprehensible por analogía con su función actual, lo que permite ser comprendida y disfrutada en el presente, es decir, no se requiere de una compleja decodificación para entender mensajes acerca de su significado. Representa un tipo muy explicativo de la importancia del "valor de antigüedad" o "valor de lo antiguo" definido por Riegl en 1903, quien de modo anticipatorio advierte el peso que este valor adquirirá en la sociedad de masas. Las marcas del tiempo sobre los monumentos suscitan en el público sentimientos "vagamente estéticos", decía Riegl. Mientras que el valor histórico remite a un saber (que es necesario poseer para poder decodificar), el valor de antigüedad es perceptible por todos, es captado con facilidad por el público masivo, es más, produce una seducción particular que será premonitoriamente anunciada por Riegl como el valor dominante en los monumentos del siglo XX. Es este el carácter democrático y universal que adquieren los monumentos (noción extendida al patrimonio cultural) porque el valor de antigüedad, al basarse en los mecanismos perceptivos que posee todo sujeto, le permite captar las huellas que el paso del tiempo ha dejado en un monumento, lo cual produce la activación de un sentimiento personal e individual sobre el devenir histórico, sobre la existencia de un determinado objeto como parte del pasado.

Finalmente, el tipo de propiedad de la mayoría de las viviendas ubica a este conjunto de obras en una situación de particular vulnerabilidad, como patrimonio privado, a diferencia de los edificios del equipamiento urbano, el patrimonio industrial o religioso y de empresas de servicios, cuyo enclave en lo social potencia su condición de "público" y, por ende, promueve su protección. Para las viviendas patrimoniales no existe, en ningún municipio del área metropolitana, un plan de salvaguarda que las incluya; su conservación depende casi exclusivamente de la valorización y la voluntad de los propietarios quienes en ocasiones deben sortear las dificultades que impone la rígida reglamentación municipal y vencer las tentaciones de venta y demolición que pone en juego el mercado inmobiliario.

Sin embargo, consideramos que es posible y viable la conservación de todas estas obras, en su gran mayoría en buen estado de conservación, buscando elaborar planes de manejo a partir de la gestión de proyectos que contemplen nuevosy adecuados usos cuando no sea posible mantener la función residencial.

\section{Referencias}

Cirvini, S. et al. (2009). Patrimonio arquitectónico del área metropolitana de Mendoza (CDRom). Buenos Aires: Conicet.

Cirvini, S. y Raffa, C. (2010). El patrimonio cultural del área metropolitana de Mendoza (Argentina). Propuestas metodológicas para su evaluación como recurso en proyectos de desarrollo local. Apuntes, 23(2), 222-235.

Guitián, D. (2007). Los bienes culturales en el espacio habitable. Argos, 24(47), 28-41.

Ponte, J. R. (2005). De los caciques del agua a la Mendoza de las acequias: Cinco siglos de historia de acequias, zanjones y molinos. Mendoza: Unidad Ciudad y Territorio del Incihusa - Conicet.

Riegl, A. (1999 [1903]). El culto moderno a los monumentos. Madrid: La Balsa de la Medusa. 